\title{
Effect of Parathyroid Hormone on Osmotic Fragility of
}

\section{Human Erythrocytes}

\author{
Eitan Bogin, Shaul G. Massry, Joseph Levi, Meir Djaldeti, Greg Bristol, and \\ JacQueline Smith, Division of Nephrology and Department of Medicine, \\ University of Southern California School of Medicine, Los Angeles, \\ California 90033; Division of Nephrology and Department of Medicine, \\ Hasharon Hospital, Petah Tiqva, Israel
}

A B S T RACT The survival of erythrocytes (RBC) is shortened in uremia, and it has been shown that calcium influx into RBC evoked crenation and increased their rigidity. The high blood levels of parathyroid hormone (PTH) may augment entry of calcium into RBC and hence affect their integrity. We examined the effect of PTH on osmotic fragility of human RBC and investigated the mechanisms through which PTH interacts with RBC.

Both the amino-terminal (1-34) PTH and the intact (1-84) PTH, but not the carboxy-terminal (53-84) $\mathrm{PTH}$, produced significant increases in osmotic fragility. This effect was abolished by prior inactivation of the hormone. There was a dose-response relationship between both moieties of PTH and the increase in osmotic fragility. This action of PTH required calcium, was mimicked by calcium ionophore, and was partially blocked by verapamil. PTH caused significant influx of ${ }^{45} \mathrm{Ca}$ into $\mathrm{RBC}$, which was not associated with potassium leak. The hormone did not affect water content of RBC. Scanning electron microscopy revealed that the incubation of RBC with PTH was associated with the appearance of membrane filamentous extensions, which anchor RBC together.

Inhibition of glycolytic activity of $\mathrm{RBC}$ with $\mathrm{NaF}$ or inhibition of Na-K-activated ATPase with ouabain did not abolish the effect of PTH on osmotic fragility. PTH did not stimulate RBC Na-K-activated ATPase or Mg-dependent ATPase but caused marked and significant stimulation of Ca-activated ATPase. The basal activity of the RBC adenylate cyclase was low and PTH produced only a modest stimulation of this enzyme. Both cyclic AMP and dibutyryl cyclic AMP had no effect on osmotic fragility.

The data indicate that: $(a)$ the $\mathrm{RBC}$ is a target organ for PTH, (b) the hormone increases osmotic fragility

Received for publication 10 August 1981 and in revised form 7 December 1981. of RBC, and $(c)$ this effect of PTH is due to enhanced calcium entry into RBC. We suggest that the increased calcium influx may affect the spectrin-actin of the cytoskeletal network of the RBC and may alter the stability and integrity of the cell membrane. This action of PTH on the RBC could be, at least in part, responsible for the shortened survival of $\mathrm{RBC}$ in uremia, and assign a new role for PTH in the pathogenesis of the anemia of uremia.

\section{INTRODUCTION}

Erythrocyte $(\mathrm{RBC})^{1}$ survival is reduced in patients with advanced renal failure $(1,2)$. Since RBC from uremic patients have normal survival when infused into normal subjects, whereas RBC from normal individuals display shortened survival when infused into uremic patients, one or more extracorpuscular factors have been considered responsible for this phenomenon $(2,4)$.

Evaluation of RBC survival of patients treated with maintenance hemodialysis using ${ }^{51} \mathrm{Cr}$ and $\mathrm{Di}$ (isopropofluro) ${ }^{32} \mathrm{P}$ techniques revealed that the half-life of the $\mathrm{RBC}$ is markedly reduced (5) and that increasing the frequency of dialysis did not normalize the halflife of the cells (6). These observations indicate that the serum factor (or factors) responsible for the reduced survival of the RBC was not effectively removed by dialysis. The nature of the hemolytic factor(s) in uremia has not, as yet, been elucidated.

Patients with chronic renal failure have secondary hyperparathyroidism (7) and markedly elevated blood levels of parathyroid hormone (PTH) $(8,9)$. This hormone is known to augment entry of calcium into a variety of mammalian cells (10-12), and it has been

${ }^{1}$ Abbreviations used in this paper: MOF, median osmotic fragility; PBS, phosphate-buffered saline; PTH, parathyroid hormone; RBC, erythrocyte. 
shown that excess blood levels of PTH in uremia are responsible for an increase in the calcium content of many tissues such as skin (13), cornea (14), blood vessels (15), muscle (16), brain (17), peripheral nerves (18), and heart (19).

Theoretically, PTH may also promote calcium entry into $\mathrm{RBC}$, and it has been shown that small increases in intracellular calcium of RBC evoked crenation and increased rigidity (20-24). Thus, excess blood levels of PTH in patients with uremia could be, at least in part, responsible for the reduced survival of $R B C$ in these patients. The present study examined the effects of PTH on RBC.

\section{METHODS}

The osmotic fragility of human RBC was evaluated by the method of Parpart et al. (25). Blood samples were withdrawn into heparinized test tubes from normal volunteers. The samples were centrifuged for $5 \mathrm{~min}$ at $600 \mathrm{~g}$ and both the plasma and the buffy coat were discarded. The packed RBC were washed three times. The first two washes were made with $6 \mathrm{vol}$ of a solution containing $0.9 \% \mathrm{NaCl}$ and $10 \mu \mathrm{M}$ EDTA, and the final wash with isotonic phosphate-buffered saline (PBS), pH 7.4, containing $100 \mathrm{mg} / 100 \mathrm{ml}$ bovine serum albumin. Each time, the RBC were mixed with the solution by gentle inversion and centrifuged for $3 \mathrm{~min}$ at $600 \mathrm{~g}$. The washed packed RBC were then suspended in PBS to provide a hematocrit of $10 \%$. We first measured the median osmotic fragility (MOF) for $\mathrm{RBC}$ of each individual by incubating $50 \mu \mathrm{l}$ of the RBC in solutions containing various concentrations of $\mathrm{NaCl}$. The absorbance of the supernate vs. water was determined with Beckman spectrophotometer (Beckman Instruments, Inc., Fullerton, CA) at $\mathbf{5 7 5} \mu \mathrm{m}$, and the percentage of RBC lysed in each solution was calculated. The concentration at which $50 \%$ of RBC were lysed was considered the MOF. These studies also allowed the construction of osmotic fragility curves.

The effects of the various experimental conditions on the osmotic fragility of the RBC were examined by the same procedure described above. Two sets of test tubes were prepared to study hemolysis in the absence (control) and presence of the experimental condition. The test materials were added to the PBS without changing the volume of the solution or the concentration of $\mathrm{NaCl}$. All studies were performed in duplicate.

Preliminary studies showed that the intact molecule of PTH causes hemolysis of RBC. Therefore, we evaluated the effects of various concentrations $(0.1,1.0$, and $10.0 \mathrm{U} / \mathrm{ml})$ of the intact hormone 1-84 bPTH (Sigma Chemical Co., St. Louis, MO), of its amino-terminal fragment 1-34 bPTH (Beckman Instruments, Inc., Spinco Div., Palo Alto, CA), of $1.2 \mu \mathrm{g} / \mathrm{ml}$ of the commercially available carboxy-terminal fragment 53-84 hPTH (Bachem Inc., Marina Del Rey, CA), and of inactivated PTH on the osmotic fragility of human RBC. All studies were performed with PBS solution containing $1.0 \mathrm{mM}$ calcium. $1.2 \mu \mathrm{g}$ of $53-84 \mathrm{hPTH}$ is equivalent to $10 \mathrm{U}$ of 1-84 bPTH. Inactivation of the hormone was done as follows: 10-15 $\mu \mathrm{g}$ of PTH was dissolved in $60 \mu \mathrm{l}$ of 0.15 $\mathrm{N}$ acetic acid, and to this solution $40 \mu \mathrm{l}$ of $30 \% \mathrm{vol} / \mathrm{vol} \mathrm{H}_{2} \mathrm{O}_{2}$ was added. The solution was incubated at $37^{\circ} \mathrm{C}$ for $45 \mathrm{~min}$ and the reaction was terminated by freezing and lyophilizing. The effects of various concentrations of calcium $(0,0.01$, 0.10 , and $1.0 \mathrm{mM}$ ) in PBS on the action of PTH on osmotic fragility of RBC were also examined. To ensure that the PBS was free of calcium, studies were also performed with calcium-free PBS to which 1 mM EDTA was added. The MOF in the presence of PTH with and without EDTA in the calcium-free PBS was not different. Studies were also carried out to examine the effect of preincubation of RBC with PTH in isotonic PBS containing $1 \mathrm{mM}$ calcium for $30 \mathrm{~min}$. The cells were then washed three times with isotonic PBS without PTH and their osmotic fragility was then determined.

The effects of $10 \mu \mathrm{M}$ cyclic AMP (Sigma Chemical Co.) and $1 \mu \mathrm{M}$ diluetyryl cyclic AMP (Sigma Chemical Co.) in the absence and presence of $1.0 \mathrm{mM}$ calcium on osmotic fragility of RBC were also evaluated.

Studies were also done to investigate whether the effect of PTH on RBC is mimicked by the free acid form of calcium ionophore A23187, which contains no calcium (kindly supplied by Eli Lilly \& Co., Indianapolis, IN) or inhibited by verapamil (Isoptene, Knoll AG, Ludwingshagen, West Germany). We evaluated the effects of 1.0 and $10 \mu \mathrm{M}$ calcium ionophore A23187 on the osmotic fragility of the RBC in the absence of calcium and PTH and in the presence of $1.0 \mathrm{mM}$ calcium. We also examined the effect of $27.5 \mu \mathrm{M}$ verapamil alone and in the presence of PTH and compared the results with the effect of PTH alone.

The possibility that PTH may exert its effect on the osmotic fragility of the RBC through an action on glycolytic activity of the cells or on the $\mathrm{Na}-\mathrm{K}$-activated ATPase of the RBC membrane was also examined. This was done by evaluating the effect of PTH on the osmotic fragility of RBC in the presence and absence of $25 \mathrm{mM} \mathrm{NaF}$ (an inhibitor of glycolytic activity) and in the presence and absence of 2.5 $\mathrm{mM}$ ouabain (an inhibitor of Na-K-activated ATPase).

The effects of PTH on the activity of $\mathrm{Na}$-K-activated ATPase, Ca-activated ATPase, and Mg-dependent ATPase of the RBC membrane were also evaluated. Processing of the RBC for the measurements of the ATPase activity was made according to the method of Sen and Post (26) with either ouabain, EGTA, or calcium, or a combination thereof was added, depending on the enzyme assay. The activity of each enzyme was measured by hydrolysis of ATP to inorganic phosphorus, which was measured according to the method of Fiske and Subbarow (27) and expressed per milligram of protein, as determined by the method of Lowry et al. (28). Assays of the enzyme activity were done in duplicates.

Assay of adenylate cyclase activity of RBC ghosts were made in the absence and presence of $10 \mathrm{U} / \mathrm{ml}$ of PTH, according to the methods described by Bilezikian and Aurbach (29) and by Rodan et al. (30), with modifications. The ghosts were prepared according to the method of Dodge et al. (31) and their protein content was determined by the method of Lowry et al. (28). Cyclic AMP was determined by the method of Steiner et al. (32) by means of radioimmunoassay and a commercially available reagent kit from New England Nuclear (Boston, MA). Assays of the enzyme activity were done in duplicate.

The effects of PTH in the presence or absence of calcium, verapamil, or calcium ionophore A23187, and of the latter in the presence or absence of calcium or verapamil on the leakage of magnesium and potassium from RBC, were also investigated. The RBC were prepared as described above. They were then suspended in PBS containing $0.1 \%$ bovine serum, $\mathrm{pH} 7.4$, to give a hematocrit of $12.5 \%$. $100 \mu \mathrm{l}$ of the suspension $\left(1.80 \times 10^{8} \mathrm{RBC}\right)$ was added to $900 \mu \mathrm{l}$ of isotonic PBS solution containing various combinations of calcium (1 $\mathrm{mM}), 1-84$ bPTH (20 U), calcium ionophore A23187 $(1 \mu \mathrm{M})$, or verapamil $(10 \mu \mathrm{M})$. The solutions were preincubated in 
a water bath at $37^{\circ} \mathrm{C}$ for $10 \mathrm{~min}$ until the temperature reached equilibrium. The reaction was started by adding the cell suspension to the media, followed by incubation for 60 $\mathrm{min}$. The reaction was stopped after $15 \mathrm{~min}$ of centrifugation at $1,000 \mathrm{~g}$. The supernate was removed for the determinations of hemoglobin, magnesium, and potassium. Hemoglobin was measured spectrophotometrically at $575 \mu \mathrm{m}$, potassium with Instrumentation Laboratory flame photometer (Instrumentation Laboratory, Inc., Lexington, MA), and magnesium with Perkin-Elmer atomic absorption spectrophotometer model 503 (Perkin-Elmer Corp., Instrument Div., Norwalk, CT):

The effect of PTH on water content of RBC was examined in five studies. RBC were prepared as described above and the same cell population was incubated with isotonic PBS containing $1 \mathrm{mM}$ calcium in the presence and absence of PTH for $60 \mathrm{~min}$. The solutions were centrifuged for $1 \mathrm{~h}$ at 15,000 rpm. Trapped PBS was estimated by tagging the solution with ${ }^{125}$ IHSA $(0.15 \mu \mathrm{Ci} / \mathrm{ml})$. The water content was estimated by drying the sample at $105^{\circ} \mathrm{C}$ to a constant weight (generally within 24-36 h). This value was corrected for the trapped PBS solution.

We also examined the effects of PTH, calcium ionophore A23187, and verapamil on ${ }^{45} \mathrm{Ca}$ uptake by the RBC. The procedures for the preparation of the $\mathrm{RBC}$ were similar to those described above, but in these studies $100 \mu$ l of RBC suspension (12.5\% hematocrit and equal to $1.8 \times 10^{8} \mathrm{RBC}$ ) were added to $900 \mu \mathrm{l}$ of isotonic PBS solution containing 1 $\mathrm{mM}$ of calcium and $0.1 \mu \mathrm{Ci}$ of ${ }^{45} \mathrm{Ca}$. After $60 \mathrm{~min}$ of incubation, the solution was centrifuged at $15,000 \mathrm{rpm}$ for 30 min and the supernate removed. The pellet was washed and centrifuged three times with PBS containing no radioactive calcium. The radioactivity was measured in the packed cells. They were decolorized with hydrogen peroxide and counted in scintillation fluid $(619 \mathrm{ml}$ toluene, $293 \mathrm{ml}$ Triton X-100, $88 \mathrm{ml} \mathrm{H}_{2} \mathrm{O}$ containing $3.53 \mathrm{~g}$ purified protein derivative and $44 \mathrm{mg}$ POPOP).

In preliminary studies we found that PTH exerts similar effects on RBC of rabbits. Evaluation of the effects of PTH, in the presence of calcium on the morphology of the rabbit RBC was performed. The cells were prepared and the experiments were done as described above. The packed cells were fixed in $1 \%$ glutaraldehyde for evaluation with scanning electron microscope.

\section{RESULTS}

The effects of the intact molecule of PTH (1-84 bPTH), its amino-terminal fragment (1-34 bPTH), its carboxy-terminal fragment (53-84 hPTH) and of inactivated PTH on the osmotic fragility of RBC are given in Table I and Figs. 1 and 2. Both 1-84 bPTH and 1-34 bPTH produced significant increases in osmotic fragility of human RBC. The MOF increased from $0.414 \pm 0.006$ (SE) to $0.452 \pm 0.007(P<0.01)$ and to $0.454 \pm 0.007(P<0.01)$ in the presence of 1 and 10 $\mathrm{U} / \mathrm{ml}$ of 1-84 bPTH. This change in MOF rendered the RBC more susceptible to hypotonic lysis. From Fig. 1, it could be noted that at concentrations of $\mathrm{NaCl}$ that were associated with $10 \%$ hemolysis in the absence of PTH, $50 \%$ of the cells were lysed in the presence

TABLE I

Effect of PTH on MOF of Human RBC

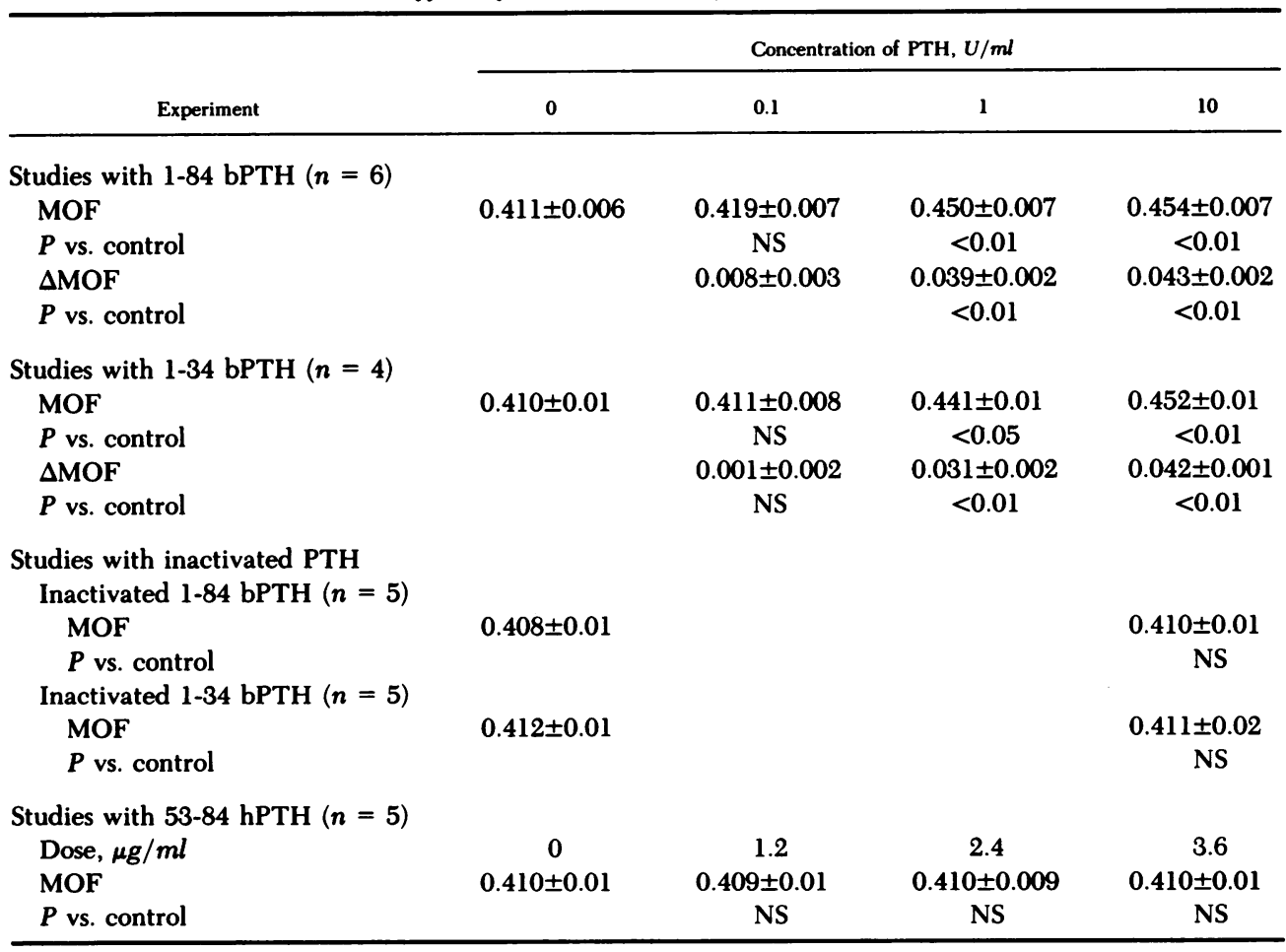



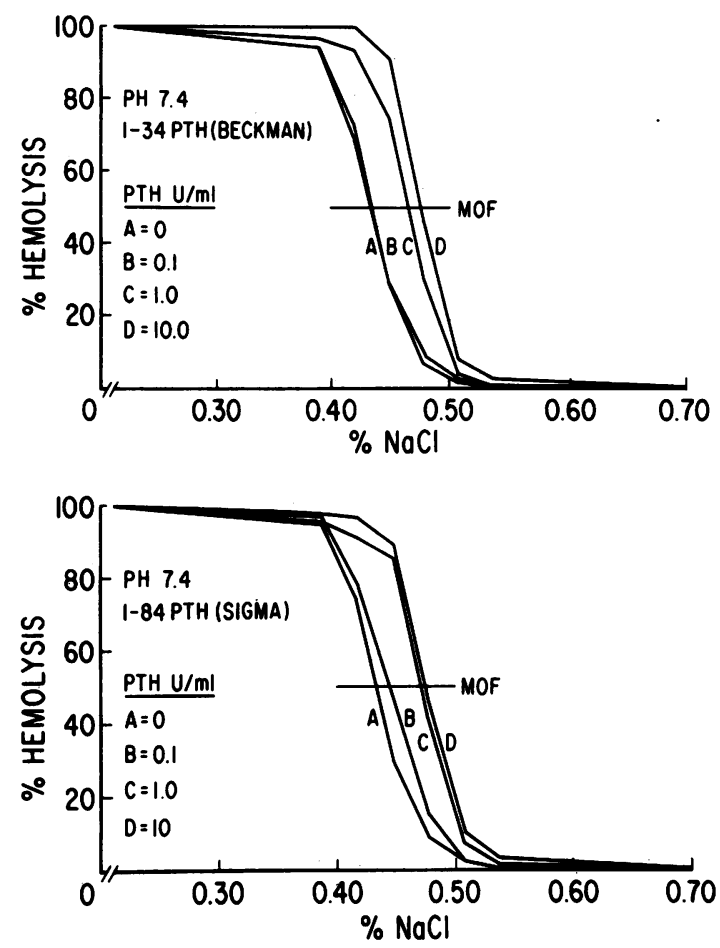

Figure 1 Effects of 1-34 PTH (upper panel) and of 1-84 PTH (lower panel) on percentage of hemolysis and MOF of human RBC.

of 1.0 or $10 \mathrm{U} / \mathrm{ml}$. These effects of 1-34 bPTH and 184 bPTH on MOF displayed a dose-response relationship (Fig. 2). Inactivation of both these moieties of PTH abolished the hemolytic action of the hormone. In contrast to 1-34 and 1-84 bPTH, the carboxy-terminal fragment 53-84 hPTH had no effect on the osmotic fragility of the RBC. Preincubation of RBC with PTH did not affect their MOF. The latter was

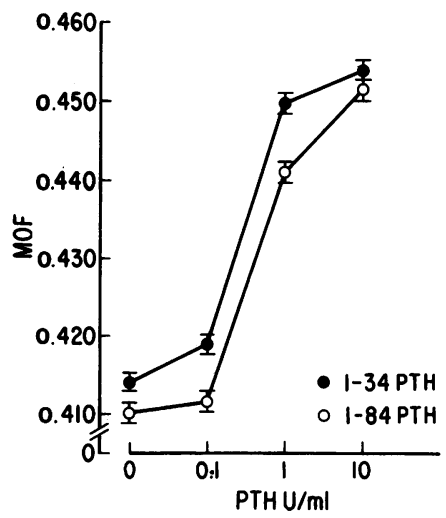

Figure 2 A dose-response curve between 1-34 PTH and 1-84 PTH and MOF of human RBC. Each data point is the mean $\pm \mathrm{SE}$ of five to seven studies.
$0.416 \pm 0.01 \quad(n=6)$ in the control studies and $0.414 \pm 0.01$ in studies with cells preincubated with PTH. These data indicate that the PTH must be present in the media to exert its effect on MOF.

Fig. 3 depicts the effects of various concentrations of calcium in PBS on the effect of $1 \mathrm{U} / \mathrm{ml}$ of $1-84$ bPTH on MOF. It is evident that in the absence of calcium, PTH did not produce a change in MOF, and there was a dose-response relationship between the calcium concentration and the change in MOF induced by PTH.

Neither NaF (an inhibitor of glycolysis) nor ouabain (an inhibitor of Na-K activated ATPase) affected the changes in MOF induced by PTH. The increase in MOF was $0.038 \pm 0.002$ with PTH alone, $0.039 \pm 0.002$ with PTH and $\mathrm{NaF}$, and $0.039 \pm 0.001$ with PTH and ouabain.

The results of the studies on the effects of the calcium ionophore A23187 on osmotic fragility of RBC are shown in Table II. The calcium ionophore $(10 \mu \mathrm{M})$ in the absence of calcium reduced MOF, and the change $(-0.034 \pm 0.002)$ was significant $(P<0.01)$. In the presence of $1 \mathrm{mM}$ calcium in PBS, this effect of calcium ionophore was not apparent and MOF increased by $0.010 \pm 0.002$. Thus, in the presence of calcium, the change in MOF equals the sum of the change induced by ionophore without calcium and that noted in the presence of calcium. The sum total is an increase in MOF of $0.044 \pm 0.002$, a change similar to that induced by PTH in the presence of calcium.

Verapamil alone did not affect the osmotic fragility of the RBC, and when used with PTH it blocked almost $50 \%$ of the effect of PTH on MOF. The change in MOF with PTH alone was $0.052 \pm 0.003$ and with PTH and verapamil it was $0.024 \pm 0.002(P<0.01)$.

The basal activity of adenylate cyclase of RBC obtained from seven studies was $3.54 \pm 0.26$ pmol cyclic $\mathrm{AMP} / 2 \mathrm{~h}$ per $\mathrm{mg}$ protein and $4.51 \pm 0.37 \mathrm{pmol}$ cyclic $\mathrm{AMP} / 2 \mathrm{~h}$ per $\mathrm{mg}$ protein in the presence of $10 \mathrm{U} / \mathrm{ml}$ bPTH. This represents a modest $(27 \pm 2 \%)$, but significant $(P<0.01$ by paired $t$ test) increment. Neither cyclic AMP nor dibutyryl cyclic AMP in the absence or presence of $1 \mathrm{mM} \mathrm{Ca}$ had an affect on the osmotic fragility of human RBC.

The effects of 1-84 bPTH on the activity of Mgdependent, Ca-activated, and $\mathrm{Na}-\mathrm{K}$-activated ATPase of the RBC are depicted in Table III. The hormone produced significant $(P<0.01)$ stimulation of the Caactivated ATPase only. The activity of the enzyme doubled in the presence of the hormone.

Calcium ionophore produced marked and significant leakage of potassium from RBC; the presence of calcium or PTH in PBS did not augment this effect and verapamil did not abolish it. Calcium ionophore also caused marked leakage of magnesium and this 
TABLE II

Effect of Calcium Ionophore A23187 on MOF of Human RBC

\begin{tabular}{lcrr}
\hline & \multicolumn{3}{c}{ Ionophore concentration, $\mu M$} \\
\cline { 2 - 4 } & 0 & 1.0 & \multicolumn{1}{c}{10} \\
\hline No calcium & & & \\
MOF & $0.428 \pm 0.03$ & $0.416 \pm 0.004$ & $0.394 \pm 0.004$ \\
$\Delta$ MOF & & $-0.012 \pm 0.002$ & $-0.034 \pm 0.002$ \\
I mM calcium & & & \\
MOF & $0.410 \pm 0.003$ & $0.413 \pm 0.003$ & $0.420 \pm 0.003$ \\
$\Delta$ MOF & & $0.003 \pm 0.002$ & $0.010 \pm 0.002$ \\
\hline
\end{tabular}

Each data point represents mean $\pm \mathrm{SE}$ of five experiments.

effect was potentiated in the presence of calcium in PBS and again was not prevented by verapamil. Significant leakage of hemoglobin occurred in the simultaneous presence of calcium and calcium ionophore in the PBS. PTH alone and in the presence of calcium and/or verapamil did not induce potassium leak, but caused modest leakage of magnesium when calcium was present in PBS; the latter effect was blunted in the presence of verapamil. There was no effect of PTH on the water content of RBC. The water content was $67 \pm 2 \%$ in the absence of PTH and $68 \pm 3 \%$ with PTH.

Summary of the data on the effect of 1-84 bPTH, calcium ionophore, verapamil, or various combinations of these agents on calcium uptake by the RBC is shown in Table IV. PTH produced significant $(P$ $<0.01$ ) calcium uptake by the RBC (from $0.09 \pm 0.01$ to $1.50 \pm 0.19 \mathrm{~m} \mu \mathrm{mol} / \mathrm{h}$ per $\left.1.8 \times 10^{8} \mathrm{RBC}\right)$. Verapamil only partially but significantly $(P<0.01)$ blocked calcium uptake induced by PTH. The uptake of calcium was most marked in the presence of calcium ionophore and was 14 times greater than that induced by PTH alone; verapamil did not block the effect of calcium ionophore or calcium uptake.

Fig. 4 depicts a scanning electron micrograph of RBC after the incubation in PBS containing 1-84
bPTH and calcium. Many RBC showed membranous processes extending toward other RBC and linking them together.

\section{DISCUSSION}

The results of the present study demonstrate that both the intact PTH and its amino-terminal fragment produced significant increases in the osmotic fragility of human RBC. This effect was dose dependent, required the presence of calcium, and was due neither to inhibition of the glycolytic activity of the cells nor to the stimulation of their $\mathrm{Na}-\mathrm{K}$-activated ATPase. The demonstration that inactivation of PTH abolished its effect on RBC is consistent with the action's being related to the biologic activity of the hormone and not to a contaminant of the hormone preparation. Furthermore, our data show that the MOF of RBC preincubation with PTH is not altered and that the hormone must be present in the media to exert its effect.

PTH is known to augment entry of calcium into a varity of mammalian cells (10-12). Two observations in our study indicate that PTH enhances calcium movement into the RBC as well. An increase in the calcium concentration in the cis-side of the RBC membrane activates the transport system responsible for the

TABLE III

Effects of $10 \mathrm{U} / \mathrm{ml}$ of 1-84 bPTH on the Activity of Mg-dependent, Ca-activated, and Na-K-activated ATPase of RBC

\begin{tabular}{lccc}
\hline & Mg-dependent ATPase & Ca-activated ATPase & Na-K-activated ATPase \\
\hline & \multicolumn{3}{c}{$n$ nol Pi/mg protein $/$ min } \\
-PTH & $62 \pm 4.5$ & $70 \pm 5.2$ & $46 \pm 3.1$ \\
+ PTH & $63 \pm 5.1(102 \pm 4.0)$ & $153 \pm 25.9(213 \pm 23.8)$ & $48 \pm 5.2(103 \pm 5.9)$ \\
$P$ & NS & 0.01 & NS \\
\hline
\end{tabular}

Data are presented as mean $\pm \mathrm{SE}$ of six studies. Numbers in brackets indicate the percentage increase from control value. 
TABLE IV

Effect of PTH, Verapamil, and Calcium Ionophore on Calcium Entry into the RBC

\begin{tabular}{lcccr}
\hline PTH & Verapamil & A23187 & Calcium entered & \multicolumn{1}{c}{ Change } \\
\hline & & & $\begin{array}{c}m \mu m o l / h / 1.8 \\
\times 10^{8} R B C\end{array}$ & $\%$ \\
& & & & \\
- & - & - & $0.09 \pm 0.01$ & 0 \\
+ & - & - & $1.50 \pm 0.19^{\circ}$ & $+1,667$ \\
- & + & - & $0.07 \pm 0.01$ & -22 \\
- & - & + & $21.00 \pm 3.90^{\circ}$ & $+23,333$ \\
+ & + & - & $1.00 \pm 0.101$ & $+1,256$ \\
- & + & + & $21.00 \pm 2.36^{\circ}$ & $+23,333$ \\
\hline
\end{tabular}

Data are presented as the mean $\pm \mathrm{SE}$ of 32 studies.

- $P<0.01$ from control.

$\ddagger P<0.01$ from PTH alone.

extrusion of this ion from the cells (33), and this system depends on the activity of Ca-activated ATPase (33). The finding that PTH stimulated the Ca-activated ATPase of the RBC is in agreement with PTH augmenting calcium entry into the cells. In addition, the results of the studies with ${ }^{45} \mathrm{Ca}$ provide direct evidence that PTH increases calcium uptake by the RBC. The mechanisms through which PTH augments calcium influx into the RBC are not fully elucidated by the present study. This action of the hormone could be mediated by increased production of cyclic AMP via the stimulation of an adenylate cyclase. But the finding that PTH caused only a modest stimulation of the activity of the RBC adenylate cyclase and the observation that both cyclic AMP and dibutyryl cyclic AMP did not have an effect on the osmotic fragility of the cells make this possibility unlikely.

The hormone may, however, directly enhance calcium influx into the RBC. Such an action of PTH could be due to an effect of the hormone on the phospholipids of the cell membrane. Lo et al. (34) reported

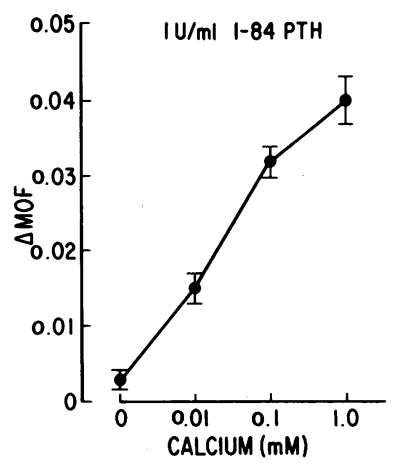

Figure 3 Effect of calcium on the change in MOF induced by $1 \mathrm{U} / \mathrm{ml}$ of $1-84 \mathrm{PTH}$. that PTH increased the incorporation of ${ }^{32} \mathrm{Pi}$ into phosphatidic acids and phosphatidylinositol in renal cortical slices. Mitchel (35) found that the incorporation of ${ }^{32} \mathrm{Pi}$ into these components precedes the movement of calcium across cell membrane. Finally, Green et al. (36) showed that phosphatidic acid and phosphatidylinositol are potent calcium ionophores.

Several findings in our study provide support for the notion that the action of PTH on the osmotic fragility of the RBC is related to the enhanced calcium entry into the cells. First, PTH did not exert its effect in the absence of calcium in the media. Second, calcium ionophore in the presence of calcium produced an effect on osmotic fragility similar to that of PTH. Third, verapamil, which blocks movement of calcium into cells, blocked partially but significantly the effect of the hormone on the osmotic fragility.

The cellular events leading to an increase in osmotic fragility of the RBC by the PTH-mediated increment in calcium influx are not evident. Several possibilities should be considered. First, it has been reported that calcium loading of RBC by ionophore is associated with marked potassium loss and shrinkage of the cells (37). The latter changes do not appear to play a role in the effect of PTH on osmotic fragility, since the enhanced calcium influx produced by PTH was not associated with potassium loss from the cells.

Second, augmented calcium influx into the RBC (38, 39) and stimulation of calcium-activated ATPase (33, 39) utilize ATP, which results in ATP depletion. Recent studies suggest that ATP may have a direct effect on membrane flexibility by affecting membrane-associated structural proteins $(40,41)$. Thus, ATP depletion may affect membrane stability and lead to cell fragmentation.

Third, the RBC have a membrane skeleton located at the membrane-cytosal surface with its major component made of spectrin-actin $(42,43)$ and this cystoskeletal network of the RBC participates in several membrane functions, including control of shape, viscoelastic properties, surface topology, and membrane stability (42-44). An increase in calcium concentration of RBC causes cross linking of membrane proteins of intact cells and it has been suggested that the intrinsic cross linking of membrane proteins is a key signal for the removal of the RBC from the circulation (45). It is possible that $\mathrm{PTH}$, by enhancing calcium influx into $\mathrm{RBC}$, causes cross linking of membrane proteins and as a result affects membrane structure and stability. That PTH may have an effect on the RBC membrane is further supported by the finding of filamentous extensions with scanning electron microscopy. PTH may also reduce $\mathrm{RBC}$ surface area by liberation of membrane vesicles and/or by lipid or protein loss; further studies to examine these possibilities are needed. 

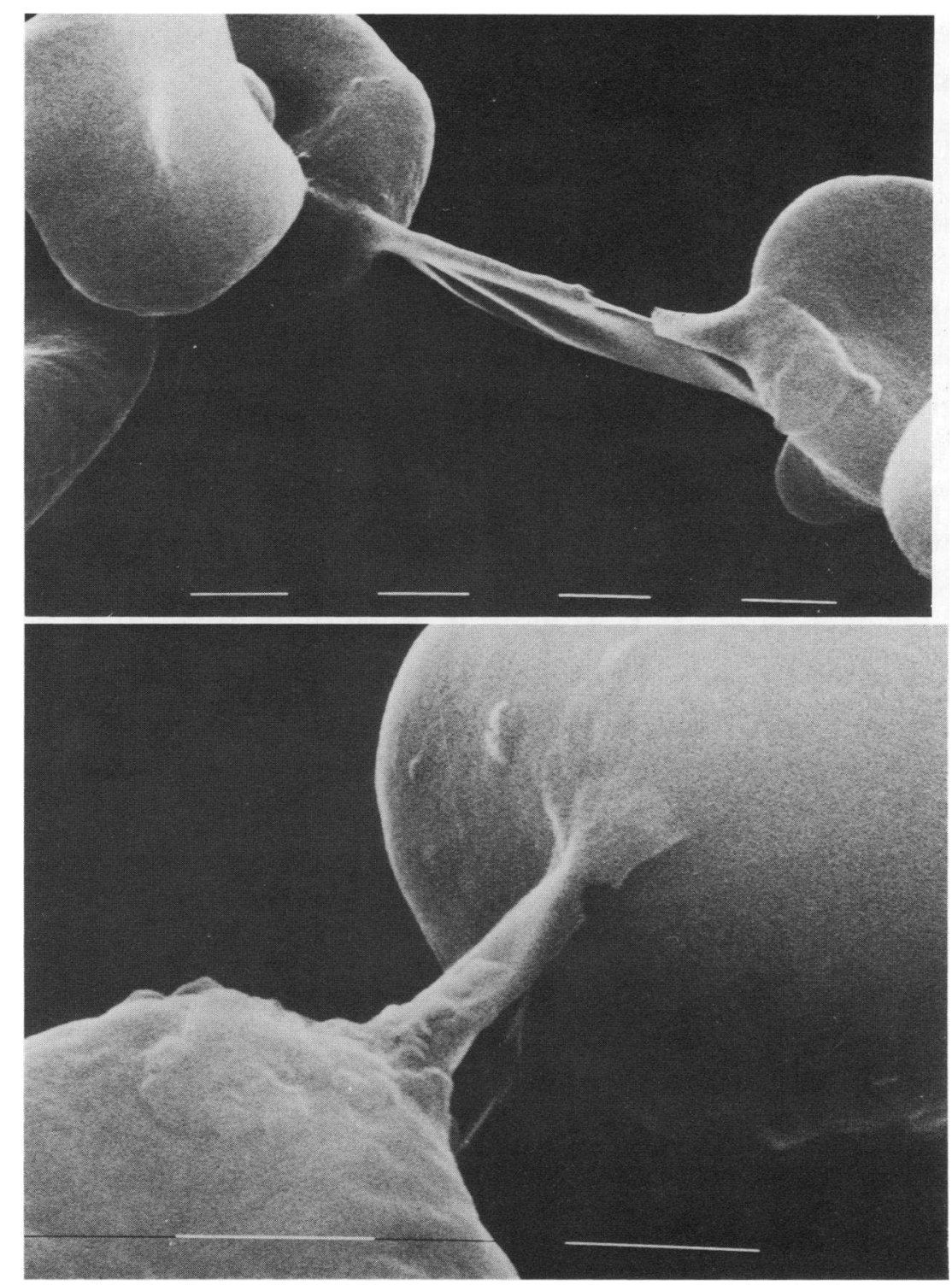

FIGURE 4 Scanning electron micrograph depicting the filamentous extension from the RBC membranes and adhesions between cells (upper panel) and (lower panel) close-up photograph. Marker is $1.0 \mu \mathrm{m}$.

Since the osmotic fragility of a given $\mathrm{RBC}$ represents a measure of its surface area/volume ratio and since PTH did not affect water content of $\mathrm{RBC}$, it is reasonable to suggest that the effect of the hormone on MOF is mediated through a reduction in surface area secondary to changes in cell membrane shape and/or integrity.

The results of the present study and those previously reported by us (46) and others (47-49) provide information on the multiple and complex pathways through which excess blood levels of PTH in patients with uremia may participate in the genesis of their anemia. There are at least three pathogenetic mechanisms. PTH inhibits erythropoiesis $(46,49)$, affects RBC survival, and produces bone marrow fibrosis $(48,49)$, which reduces the availability of the red marrow to produce erythrocytes.

\section{ACKNOWLEDGMENTS}

The authors would like to thank Ms. Jamie Jimenez for her secretarial assistance in the preparation of this paper. 
This work was supported by contract AM7-2218 and grant AM 29955 from the National Institute of Arthritis, Diabetes, and Digestive and Kidney Diseases.

\section{REFERENCES}

1. Joske, R. A., J. M. McAlister, and T. A. J. Prankerd. 1956. Isotope investigations of red cell production and destruction in chronic renal disease. Clin. Sci. (Oxf.). 15: 511522.

2. Kuroyanagi, T. 1961. Anemia associated with chronic renal failure with special reference to kinetics of erythron. Acta Haematol. Jpn. 24: 48-65.

3. Shaw, A. B. 1967. Haemolysis in chronic renal failure. Br. Med. J. 1: 213-216.

4. Loge, J. P., R. D. Lange, and C. V. Moore. 1958. Characterization of the anemia associated with chronic renal insufficiency. Am. J. Med. 24: 4-18.

5. Nathan, D. G., E. Schupak, F. Stohlman, Jr., and J. P. Merrill. 1964. Erythropoiesis in anephric man. J. Clin. Invest. 43: 2158-2165.

6. Kominami, N., E. G. Lowrie, L. E. Ianberg, A. Skaren, C. L. Hampers, J. P. Merrill, and R. D. Lange. 1971. The effect of total nephrectomy on hematopoiesis in patients undergoing chronic hemodialysis. J. Lab. Clin. Med. 78: 524-532.

7. Roth, S. I., and R. B. Marshall. 1969. Pathology and ultrastructure of the human parathyroid glands in chronic renal failure. Arch. Intern. Med. 124: 397-407.

8. Berson, S. A., and R. S. Yallow. 1966. Parathyroid hormone in plasma in adenomatous hyperparathyroidism, uremia, and bronchogenic carcinoma. Sciences (N. Y.) 154: 907-909.

9. Massry, S. G., J. W. Coburn, M. Peacock, and C. R. Kleeman. 1972. Turnover of endogenous parathyroid hormone in uremic patients and those undergoing hemodialysis. Trans. Am. Soc. Artif. Intern. Organs. 8: 416-422.

10. Wallach, S., J. V. Ballavia, J. Shorr, and J. Schaffers. 1966. Tissue distributions of electrolytes, $\mathrm{Ca}^{47}$, and $\mathrm{Mg}^{28}$ in experimental hyper- and hypoparathyroidism. Endocrinology. 78: 16-28.

11. Chausmer, A. B., B. S. Sherman, and S. Wallach. 1972. The effect of parathyroid hormone on hepatic cell transport of calcium. Endocrinology. 90: 663-672.

12. Borle, A. B. 1973. Calcium metabolism at the cellular level. Fed. Proc. 30: 1944-1950.

13. Massry, S. G., J. W. Coburn, D. L. Hartenbower, J. H. Shinaberger, J. R. DePalma, E. Chapman, and C. R. Kleeman. 1970. Mineral content of human skin in uremia: Effect of secondary hyperparathyroidism and hemodialysis. Proc. Eur. Dialysis Transplant Ass. 7: 146150.

14. Berkow, J. W., B. S. Fine, and L. E. Zimmerman. 1968. Unusual ocular calcification in hyperparathyroidism. Am. J. Ophthalmol. 66: 812-824.

15. Bernstein, D. S., P. Pletka, R. S. Hattner, C. L. Hanyers, and J.P. Merrill. 1971. Effect of total parathyroidectomy and uremia on the chemical composition of bone, skin, and aorta in the rat. Isr. J. Med. Sci. 7: 513-514.

16. Guisado, R., A. I. Arieff, and S. G. Massry. 1977. Muscle, water, and electrolytes in uremia and the effects of hemodialysis. J. Lab. Clin. Med. 89: 322-331.

17. Arieff, A. I., and S. G. Massry. 1974. Calcium metabolism of brain in acute renal failure. J. Clin. Invest. 53: 387-392.

18. Goldstein, D. A., L. A. Chui, and S. G. Massry. 1978.
Effect of parathyroid hormone and uremia on peripheral nerve calcium and motor nerve conduction velocity. $J$. Clin. Invest. 62: 88-93.

19. Kraikipanitch, S., R. D. Lindeman, A. A. Yoenice, D. J. Baxter, C. C. Haygood, and M. M. Blue. 1978. Effect of azotemia on myocardial accumulation of calcium. Mineral Electrolyte Metab. 1: 12-20.

20. Weed, R. I., P. L. LaCelle, and E. W. Merrill. 1969. Metabolic dependence of red cell deformability. J. Clin. Invest. 48: 795-809.

21. LaCelle, P. L., F. H. Kirkpatrick, and M. Udkow. 1973. Relation of altered deformability ATP, DPG, and $\mathrm{Ca}^{++}$ concentrations in senescent erythrocytes. In Erythrocyte, Thrombocytes, and Leukocytes. E. Gerlach, K. Moser, E. Deutsch, and W. Wilmanns, editors. Thieme, Stuttgart. 49-52.

22. White, J. G. 1974. Effects of an ionophore, A23187, on the surface morphology of normal erythrocytes. Am. J. Pathol. 77: 507-514.

23. Dunn, M. J. 1974. Red blood cell calcium and magnesium: effects upon sodium and potassium transport and cellular morphology. Biochim. Biophys. Acta. 352: 97116.

24. Sarkadi, B., I. Szasz, and G. Gardos. 1976. The use of ionophores of rapid loading of human red cells with radioactive cations for cation-pump studies. J. Membr. Biol. 26: 257-270.

25. Parpart, A. K., P. B. Lorenz, E. R. Parpart, J. R. Gregg and A. M. Chase. 1947. The osmotic resistance (fragility) of human red cells. J. Clin. Invest. 26: 636-640.

26. Sen, A. K., and R. L. Post. 1964. Stoichiometry and localization of adenosine and triphosphate-dependent sodium and potassium transport in the erythrocytes. $J$. Biol. Chem. 239: 345-352.

27. Fiske, C. H., and Y. Subbarow. 1925. The colorimetric determinations of phosphorus. J. Biol. Chem. 66: 375400.

28. Lowry, O. H., N. J. Rosebrough, A. L. Farr, and R. J Randall. 1951. Protein measurement with the Folin phenol reagent. J. Biol. Chem. 193: 265-275.

29. Bilezikian, J. P., and G. D. Aurbach. 1973. A $\beta$-adrenergic receptor of the turkey erythrocyte. I. Binding of catecholamine and relationship to adenylate cyclase activity. J. Biol. Chem. 248: 5575-5583.

30. Rodan, S. G., G. A. Rodan, and R. I. Shaafi. 1976. Demonstration of adenylate cyclase activity in human red blood ghosts. Biochim. Biophys. Acta. 428: 509-515.

31. Dodge, J. T., C. Mitchell, and D. J. Hanahan. 1963. The preparation and chemical characteristics of hemoglobinfree ghosts of human erythrocytes. Arch. Biochem. Biophys. 100: 119-130.

32. Steiner, A. L., A. S. Pagliara, L. R. Chase, and D. M Kipnis. 1972. Radioimmunoassay for cyclic nucleotides. II. Adenosine $3^{\prime}, 5^{\prime}$ monophosphate and guanosine $3,5^{\prime}$ monophosphate in mammalian tissue and body fluids. J. Biol. Chem. 247: 1114-1120.

33. Sarkadi, B. 1980 . Active calcium transport in human red cells. Biochim. Biophys. Acta. 604: 159-190.

34. Lo, H., D. C. Lehotay, D. Katz, and G. S. Levey. 1976 Parathyroid hormone-mediated incorporation of ${ }^{32} \mathrm{P}$-orthophosphate into phosphatidic acid and phosphatidylinositol in renal cortical slices. Endocrine Research Communications 3: 377-385.

35. Mitchel, R. H. 1975. Inositol phospholipids and cell surface receptor function. Biochim. Biophys. Acta. 415: $81-$ 147.

36. Green, D. E., M. Fry, and G. A. Blondin. 1980. Phos- 
pholipids as the molecular instruments of ion and solute transport in biological membrane. Proc. Natl. Acad. Sci. U. S. A. 77: 257-261.

37. Kirkpatrick, F. H., D. G. Hillman, and P. L. LaCelle. 1975. A23187 and red cells. Changes in deformability. $\mathrm{K}^{+}, \mathrm{Mg}^{++}, \mathrm{Ca}^{++}$, and ATP. Experientia (Basel). 37: 653654.

38. Reed, P. W. 1976. Effects of the divalent cation ionophore A23187 on potassium permeability of rat erythrocytes. J. Biol. Chem. 254: 3489-3494.

39. Taylor, D., R. Baker, and P. Hochstein. 1977. The effect of calcium ionophore A23187 on the ATP levels of human erythrocyte. Biochem. Biophys. Res. Commun 76: 205-211.

40. Birchmeier, W., and S. J. Singer. 1977. On the mechanism of ATP-induced shape changes in human erythrocyte membranes. II. Role of ATP. J. Cell Biol. 73: 647659.

41. Lutz, H. V., S. C. Liu, and J. Palek. 1977. Release of spectrin-free vesicles from human erythrocytes during ATP depletion. J. Cell Biol. 73: 548-560.

42. Steck, T. L. 1974. The organization of proteins in the human red blood cell membrane. J. Cell Biol. 62: 1-19.

43. Lux, S. E. 1979. Spectrin-actin membrane skeleton of normal and abnormal red blood cells. Semin. Hematol. 16: 21-5l.

44. Kirkpatrick, F. H. 1976. Spectrin: current understanding of its physical, biochemical, and functional properties. Life Sci. 19: 1-17.

45. Siefring, G. E., and L. Lorand. 1978. $\mathrm{Ca}^{2+}$-modulated crosslinking of membrane proteins in intact erythrocyte. In Erythrocyte Membranes: Recent Clinical and Experimental Advances. W. Kruckeberg, J. Eaton, and G. Brewer, editors. Alan R. Liss, Inc., New York. 25-32.

46. Meytes, D., E. Gobin, A. Ma, P. P. Dukes, and S. G. Massry. 1981. Effects of parathyroid hormone on erythropoiesis. J. Clin. Invest. 67: 1263-1269.

47. Levi, J., H. Bessler, I. Hirsch, and M. Djaldeti. 1979. Increased RNA and heme synthesis in mouse erythroid precursors by parathryoid hormone. Acta Haematol. Jpn. 61: 125-129.

48. Weinberg, S. G., A. Lubin, S. N. Weiner, M. P. Deoras, M. K. Ghose, and R. C. Kopelman. 1977. Myelofibrosis and renal osteodystrophy. Am. J. Med. 63: 755-764.

49. Malluche, H. H., D. A. Goldstein, and S. G. Massry. 1979. Management of renal osteodystrophy with $1,25(\mathrm{OH})_{2} \mathrm{D}_{3}$. II. Effects on histopathology of bone: evidence for healing of osteomalacia. Mineral Electrolyte Metab. 2: 4855 . 